Lise Piquilloud

Laurence Vignaux

Emilie Bialais

Jean Roeseler

Thierry Sottiaux

Pierre-François Laterre

Philippe Jolliet

Didier Tassaux

\section{Neurally adjusted ventilatory assist improves patient-ventilator interaction}

Received: 6 March 2010

Accepted: 25 July 2010

Published online: 25 September 2010

(C) Copyright jointly held by Springer and ESICM 2010

Electronic supplementary material The online version of this article (doi:10.1007/s00134-010-2052-9) contains supplementary material, which is available to authorized users.

L. Piquilloud $(\bowtie) \cdot$ L. Vignaux ·

D. Tassaux

Intensive Care Unit, Clinical Research

Laboratory, University Hospital,

Faculty of Medicine, University of Geneva,

Rue Gabrielle-Perret-Gentil 4,

1211 Geneva 14, Switzerland

e-mail: Lise.Piquilloud@hcuge.ch

Tel.: +41-22-3727448

Fax: +41-22-3729105

E. Bialais - J. Roeseler - P.-F. Laterre Intensive Care Unit, University Hospital St.-Luc, Brussels, Belgium

T. Sottiaux Intensive Care Unit, Clinique Notre Dame de Grâce, Gosselies, Belgium
P. Jolliet

Adult Intensive Care and Burn Unit, University Hospital, Faculty of Biology and Medicine, University of Lausanne, Lausanne, Switzerland

Abstract Purpose: To determine if, compared with pressure support (PS), neurally adjusted ventilatory assist (NAVA) reduces trigger delay, inspiratory time in excess, and the number of patient-ventilator asynchronies in intubated patients. Methods: Prospective interventional study in spontaneously breathing patients intubated for acute respiratory failure. Three consecutive periods of ventilation were applied: (1) PS1, (2) NAVA, (3) PS2. Airway pressure, flow, and transesophageal diaphragmatic electromyography were continuously recorded.

Results: All results are reported as median (interquartile range, IQR). Twenty-two patients were included, $36.4 \%(8 / 22)$ having obstructive pulmonary disease. NAVA reduced trigger delay (ms): NAVA, 69 (57-85); PS1, 178 (139-245); PS2, 199 (135-256). NAVA improved expiratory synchrony: inspiratory time in excess (ms): NAVA, 126 (111-136); PS1, 204 (117-345); PS2,
220 (127-366). Total asynchrony events were reduced with NAVA (events/min): NAVA, 1.21 (0.54-3.36); PS1, 3.15 (1.18-6.40); PS2, 3.04 (1.22-5.31). The number of patients with asynchrony index (AI) $>10 \%$ was reduced by $50 \%$ with NAVA. In contrast to PS, no ineffective effort or late cycling was observed with NAVA. There was less premature cycling with NAVA (events/min): NAVA, 0.00 (0.00-0.00); PS1, 0.14 (0.00-0.41); PS2, 0.00 (0.00-0.48). More double triggering was seen with NAVA, 0.78 (0.46-2.42); PS1, 0.00 (0.00-0.04); PS2, 0.00 (0.00-0.00). Conclusions: Compared with standard PS, NAVA can improve patient-ventilator synchrony in intubated spontaneously breathing intensive care patients. Further studies should aim to determine the clinical impact of this improved synchrony.

Keywords Mechanical ventilation . Patient-ventilator interaction . Neurally adjusted ventilatory assist . Pressure support · Partial ventilatory assist 


\section{Introduction}

Use of mechanical ventilation is constantly increasing $[1,2]$ and is expected to continue rising in the near future as a consequence of an ageing population with increasingly complex disease states [3]. There has been a trend over the years towards use of ventilatory modes in which some degree of spontaneous respiratory activity is preserved, known as partial ventilator assist $[4,5]$. These modes have been shown to reduce the adverse effects of prolonged sedation [6-8], neuropathy associated with use of neuromuscular blocking agents $[9,10]$, and ventilatorinduced diaphragmatic dysfunction [11-13], while also improving gas exchange [14].

The most often used partial ventilatory assist mode is pressure support (PS) [4, 5]. PS is often well tolerated, but the difference between the ventilatory profiles of the patient and the ventilator can lead to patient-ventilator asynchrony [15-17]. Thille et al. [18] found that 24\% of intubated patients undergoing PS had severe asynchrony. Asynchrony increases respiratory muscle load [19] and is associated with longer duration of mechanical ventilation $[18,20]$, its reduction therefore being of paramount importance. Neurally adjusted ventilatory assist (NAVA) could contribute to attaining that goal. Its principle is to record the diaphragmatic electrical activity (Eadi) at the distal esophageal level by means of electrodes embedded in a nasogastric tube and to use Eadi, after proper signal treatment, to control the ventilator [21]. With NAVA, the ventilator can be triggered by the Eadi signal, delivers inspiratory assistance in proportionality to the Eadi, and is usually cycled to exhalation by the Eadi signal.

Therefore, NAVA should theoretically allow nearperfect synchrony between the patient and the ventilator. The aim of our study is to explore if, in comparison with PS, NAVA could reduce trigger delay, improve expiratory synchrony, and reduce the number of patientventilator asynchronies in intubated intensive care patients. Partial results of the current study have been previously reported in abstract form [22].

\section{Materials and methods}

This was a prospective sequential interventional study conducted in the medicosurgical intensive care units (ICUs) of two university hospitals (Geneva, Switzerland and Brussels, Belgium). The study was approved by the Ethics Committee of both participating centers.

\section{Patients}

Patients admitted to the ICU, intubated for acute respiratory failure, and ventilated by PS were eligible for inclusion in the study if they had none of the exclusion criteria described in the Electronic Supplementary Material (ESM).

\section{Ventilator}

All patients were ventilated using a Servo- $\mathrm{i}^{\circledR}$ (Maquet Critical Care, Solna, Sweden) ventilator equipped with the standard commercial version of the NAVA module and software. With NAVA, the ventilator can be triggered and cycled off by the Eadi signal. The delivered pressurization is proportional to the Eadi, which is a direct expression of the patient's inspiratory effort. Details of the ventilator's functioning under NAVA are given in the ESM.

Both PS and NAVA were applied using the same machine.

\section{Measurements}

Respiratory parameters were acquired from the Servo-i ${ }^{\circledR}$ ventilator and recorded by Servo-tracker V $4.0^{\circledR}$ software (Maquet Critical Care, Solna, Sweden). Details about the measurements are given in the ESM. The percentage of respiratory cycles triggered by the Eadi and interrupted following the Eadi criteria were also recorded by Servotracker ${ }^{\circledR}$. Recorded data were stored in a laptop computer for subsequent analysis.

\section{Experimental protocol}

After written informed consent was obtained, the patient's standard nasogastric tube was replaced by the modified NAVA tube positioned according to the manufacturer's recommendations [23]. Airway suctioning was performed before the beginning of the protocol. During the entire recording period, pressure support level, positive endexpiratory pressure (PEEP), $\mathrm{FiO}_{2}$, inspiratory trigger, and cycling off settings were maintained as set by the clinician in charge of the patient. Three sequential 20 min periods were recorded: (1) PS1, (2) NAVA with gain initially set to deliver the same peak pressure (comparable level of assist) as during the initial PS1 period and then kept at the same level during the 20 min recording, (3) PS2 with the same settings as those of period PS1. During NAVA, electrical signals recorded by the electrodes embedded in the NAVA nasogastric tube are processed automatically by the Servo- $\mathrm{i}^{\circledR}$ ventilator and used to control it [21]. Breath-by-breath analysis was performed on the recorded data by using Acqknowledge ${ }^{\circledR}$ software (Biopac Systems Inc., Goleta, CA, USA). Time parameters were determined from the flow and Eadi signals as illustrated in Fig. 1 and described in detail in the ESM. If there were artifacts on the Eadi signal or if the ventilator mode was automatically 


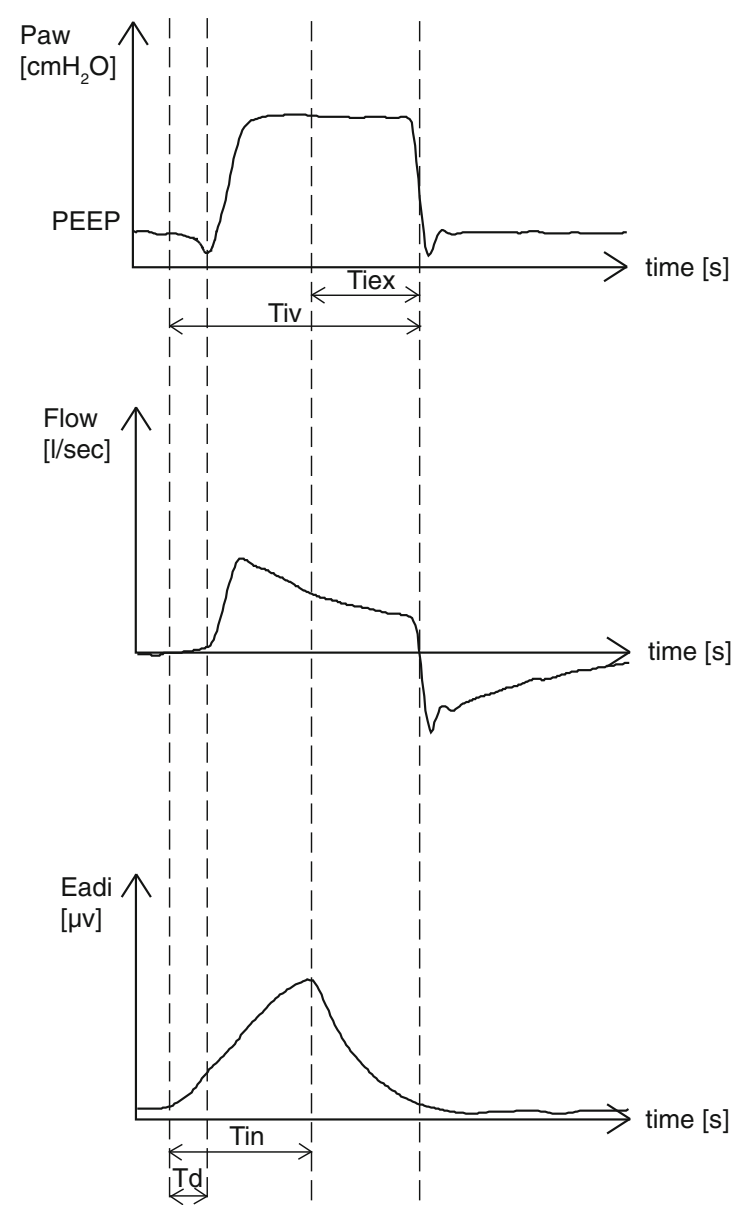

Fig. 1 Airway pressure, flow, and electrical diaphragmatic activity curves in pressure support and in neurally adjusted ventilatory assist. $P S$ pressure support, NAVA neurally adjusted ventilatory assist,

switched back from NAVA to PS (NAVA includes a builtin safety feature whereby, in case the Eadi signal became artifacted or lost, the machine automatically reverts to standard PS), the corresponding periods of time were excluded from the analysis. The total number of the five different types of patient-ventilator asynchronies described by Thille et al. [18], namely ineffective effort, autotriggering, premature cycling, delayed cycling, and double triggering, was determined for each $20 \mathrm{~min}$ recording period, based on flow and airway pressure signal as well as on the Eadi signal according to a previous publication from our group [24]. The five types of asynchronies are described in the ESM. During NAVA, we separated double triggering into two different groups, namely type 1 , when double triggering was the consequence of an Eadi cycling off criterion reached too early because of a biphasic aspect of the Eadi signal, and type 2, when the cause was different. Figure 2 provides an illustration of both types of double triggering under NAVA. The total number of asynchronies was reported as the total

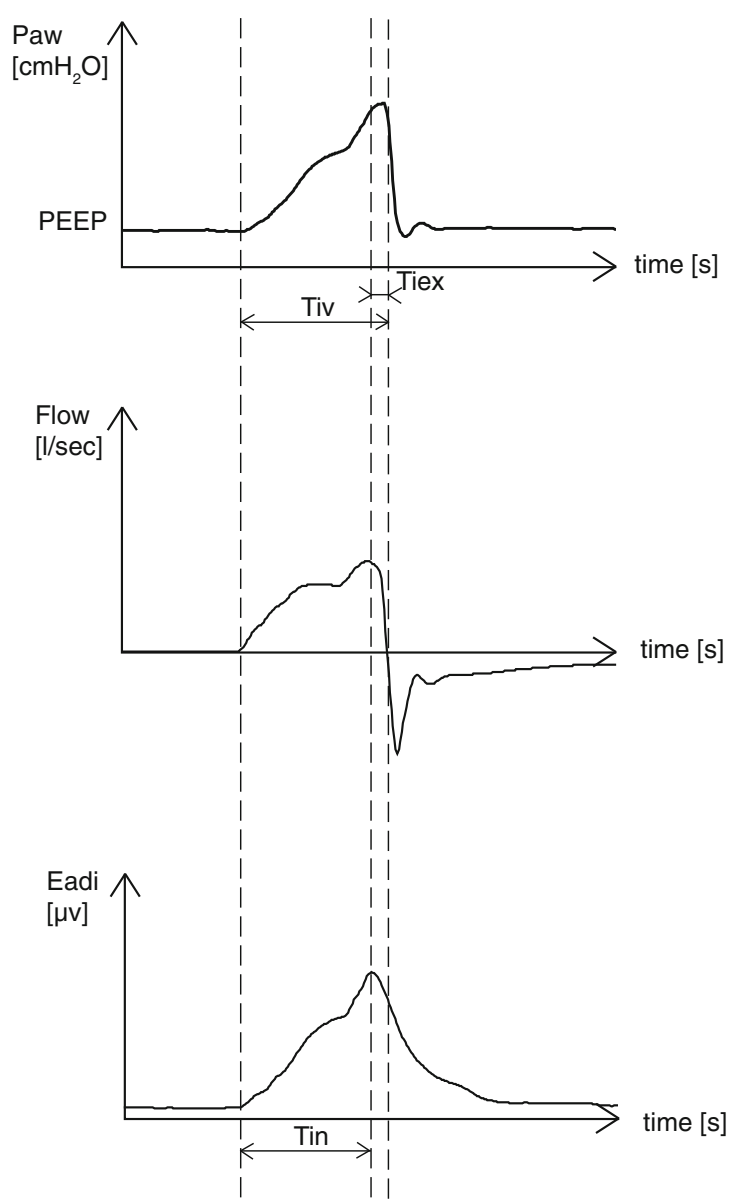

PEEP positive end-expiratory pressure, Eadi electrical activity of the diaphragm, Tiv ventilator pressurization time, Tin neural inspiratory time, $T d$ trigger delay, Tiex inspiratory time in excess

number of events per minute as well as in terms of AI, namely the total number of asynchronies given as a percentage of the total respiratory rate, computed as the sum of the ventilator respiratory rate and of the number of ineffective efforts per minute $[\mathrm{AI} \%=$ (number of asynchrony events/ventilator respiratory rate + ineffective efforts) $\times 100$ ]. The number of each type of asynchrony was reported as the total number of each event per minute. The indexed tidal volume (VTi) was defined as the tidal volume in milliliters divided by the patient's predicted body weight (PBW) in kilograms, calculated for each respiratory cycle from the tidal volume obtained from the Servo-tracker ${ }^{\circledR}$ software.

\section{Statistics}

Normality was assessed using the Kolmogorov-Smirnov test, which failed for all results; therefore, values are reported as median (IQR). Parameters reflecting patient- 

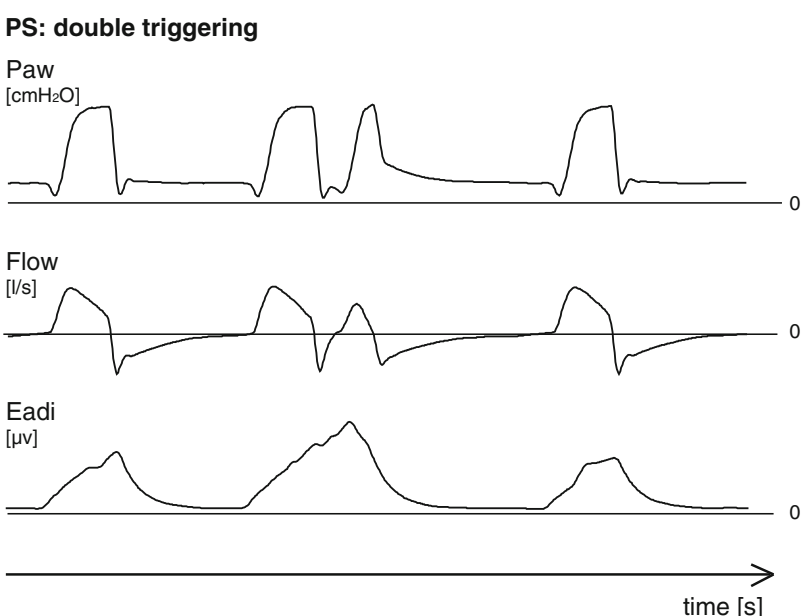

NAVA: type I double triggering
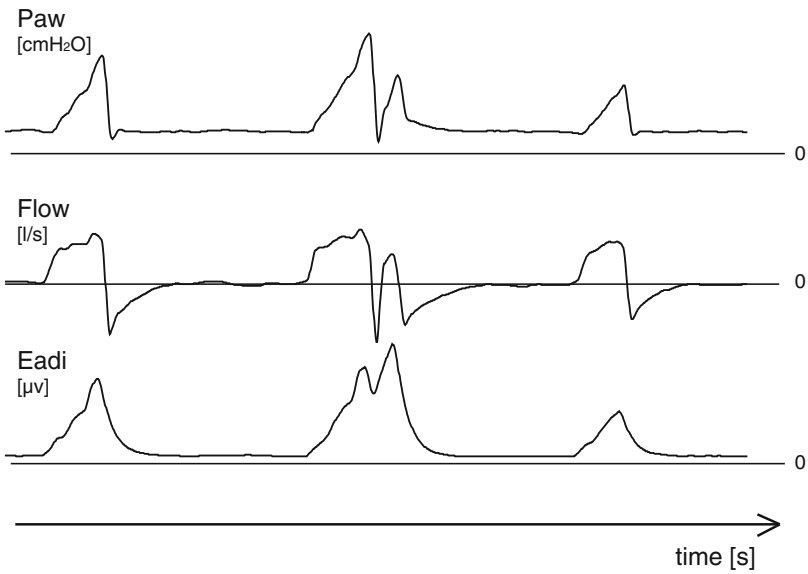

NAVA: type II double triggering
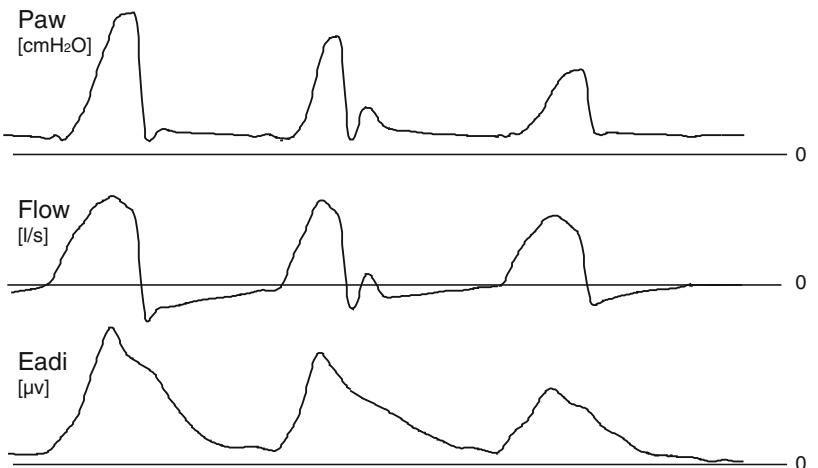

time [s]

Fig. 2 Double triggering under PS and NAVA. Paw airway pressure, Eadi electrical activity of the diaphragm

ventilator synchrony in the same subject were compared between PS1, NAVA, and PS2 using one-way repeatedmeasures analysis of variance (ANOVA) on ranks. Post hoc pairwise comparisons were performed using the Newman-Keuls procedure. Statistics were computed using SigmaStat 3.0 (SPSS, Chicago, IL, USA). For all statistical tests, the significance level was set to $p<0.05$.

\section{Results}

Twenty-five patients were included in the study. Three patients were excluded at time of analysis, one because of a final diagnosis of neuromuscular disease (exclusion criterion) and two because of nonanalyzable Eadi recording under PS.

The main characteristics of the included patients and ventilator settings are summarized in Table 1. A typical recording under NAVA and PS is shown in Fig. 3. From the total recording time of $1,320 \mathrm{~min}, 24.3 \mathrm{~min}(1.8 \%)$ was discarded from the analysis because of artifacts on the Eadi signal. From the $440 \mathrm{~min}$ of recording under NAVA, $9.4 \mathrm{~min}$ ( $2.1 \%$, corresponding to 20 events) was discarded from the analysis because of automatic reversion to PS. During NAVA, the Eadi was used to trigger $80 \%$ (58-89\%) and cycle $100 \%$ (96-100\%) of the breaths. No significant differences were found between the two PS ventilation periods in terms of trigger delay $(\mathrm{Td})$, inspiratory time in excess (Tiex), total number of asynchronies,

Table 1 Main clinical characteristics of the patients $(n=22)$ and ventilator settings

\begin{tabular}{|c|c|}
\hline \multicolumn{2}{|l|}{ Main clinical characteristics } \\
\hline Age (years) & $66 \pm 12$ \\
\hline$M: F$ & $7: 15$ \\
\hline BMI $\left(\mathrm{kg} / \mathrm{m}^{2}\right)$ & $23.4 \pm 3.1$ \\
\hline SAPS II & $48 \pm 12$ \\
\hline Days post ICU admission & $3 \pm 2$ \\
\hline Days post intubation & $3 \pm 2$ \\
\hline Known restrictive pulmonary disease $\left(n / n_{\text {tot }}\right)$ & $1 / 22(4.5 \%)$ \\
\hline Known obstructive pulmonary disease $\left(n / n_{\text {tot }}\right)$ & $8 / 22(36.4 \%)$ \\
\hline $\mathrm{PaO}_{2} / \mathrm{FiO}_{2}(\mathrm{mmHg})$ & $194.8 \pm 58.1$ \\
\hline \multicolumn{2}{|l|}{ Main ventilator settings } \\
\hline $\mathrm{FiO}_{2}$ & $0.43 \pm 0.17$ \\
\hline PEEP $\left(\mathrm{cmH}_{2} \mathrm{O}\right)$ & $7 \pm 2$ \\
\hline \multicolumn{2}{|l|}{ Inspiratory trigger in pressure support } \\
\hline Flow trigger: $1.2(1 / \mathrm{min})$ & $20 / 22$ \\
\hline Pressure trigger: -4 to $-5\left(\mathrm{cmH}_{2} \mathrm{O}\right)$ & $2 / 22$ \\
\hline Inspiratory trigger in NAVA $(\mu \mathrm{V})$ & 0.5 \\
\hline ETS in pressure support & $25-30$ \\
\hline PS level in pressure support $\left(\mathrm{cmH}_{2} \mathrm{O}\right)$ & $13 \pm 3$ \\
\hline Pressurization slope in pressure support (ms) & $100-150$ \\
\hline NAVA gain level $\left(\mathrm{cmH}_{2} \mathrm{O} / \mu \mathrm{V}\right)$ & $2.2 \pm 1.8$ \\
\hline
\end{tabular}

$M: F$ number of male and female patients, $B M I$ body mass index, SAPS II severity score SAPS II, $\mathrm{PaO}_{2} / \mathrm{FiO}_{2}$ ratio between partial pressure of oxygen in arterial blood and inspired fraction of oxygen, $\mathrm{FiO}_{2}$ inspired fraction of oxygen, PEEP positive endexpiratory pressure, ETS expiratory cycling criterion in pressure support, PS level level of assistance in pressure support, NAVA gain level level of assistance in NAVA, NAVA neurally adjusted ventilatory assist 
PS

Paw

$\left[\mathrm{cmH}_{2} \mathrm{O}\right.$ ]

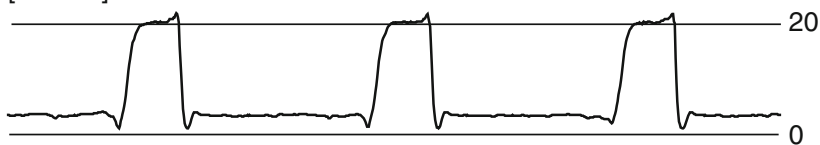

Flow

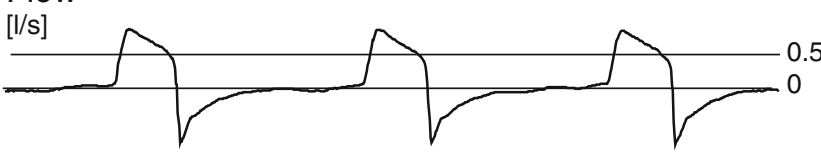

Eadi

[ $\mu \mathrm{v}]$
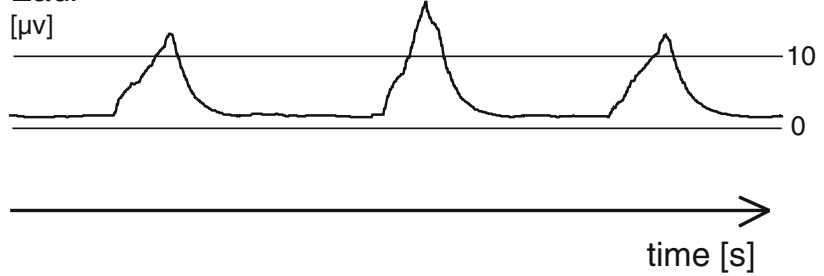

NAVA

Paw

$\left[\mathrm{cmH}_{2} \mathrm{O}\right.$ ]

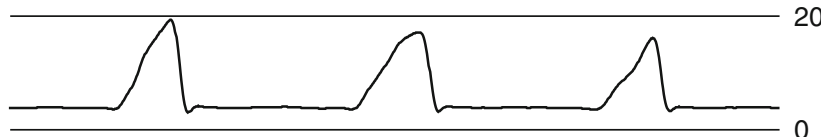

Flow

[l/s]

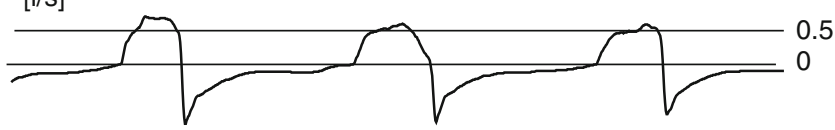

Eadi
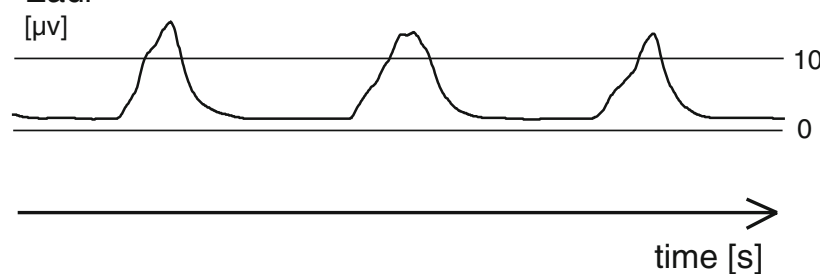

Fig. 3 Typical recording in pressure support and in NAVA. Paw airway pressure, Eadi electrical activity of the diaphragm

and number of each type of asynchrony. Detailed results of Other respiratory parameters

pairwise analysis are given in Table 2.

\section{Td and Tiex}

As shown in detail in Table 2, Td was reduced in NAVA. In NAVA, Td was below $150 \mathrm{~ms}$ for every patient, whereas in PS $16 / 22$ patients $(72.7 \%)$ had $\mathrm{Td}>150 \mathrm{~ms}$. Tiex was also reduced in NAVA.

\section{Asynchronies}

Results are summarized in Table 2, with $p$ values for ANOVA and pairwise analysis. The total number of asynchronies was significantly reduced in NAVA compared with PS1 and PS2. The median value of AI index was reduced in NAVA compared with PS1 and PS2. AI was higher than $10 \%$ in $6 / 22(27 \%)$ in NAVA and in $12 /$ $22(54.5 \%)$ and 14/22 (63.6\%) of patients in PS1 and PS2, respectively. There were neither ineffective efforts nor late cycling in NAVA. In contrast, there were ineffective efforts and late cycling in PS1 and PS2. There were fewer premature cyclings in NAVA compared with PS1 and PS2. There was no difference between NAVA and PS in terms of autotriggering. Finally, there was more double triggering in NAVA than in PS1 and PS2. Under NAVA, $63.1 \%$ of double triggerings were type 1 double triggering whereas only $36.9 \%$ were type 2 double triggering.
There was no difference in minute ventilation between NAVA and PS. VTi was lower in NAVA than in PS1 and PS2. Respiratory rate was higher in NAVA than in PS1 and PS2. Mean airway pressure (Pawm) was lower with NAVA than with PS1 and PS2. Main respiratory parameters are summarized in Table 2.

\section{Discussion}

Our results show that NAVA can improve patient-ventilator synchrony by reducing $\mathrm{Td}$, Tiex, and the total number of asynchronies compared with PS. In particular, there were no ineffective efforts or delayed cycling under NAVA.

Before discussing these results, several limitations of this study must be addressed. First, the tracings were analyzed by one investigator from Geneva, rather than one from each center, which could lead to systematic bias. However, the methodology and the reading criteria had been strictly defined before the beginning of the analysis. Moreover, in case of doubt, questionable tracings were discussed among three investigators during data session meetings to find consensus. Second, artifacted tracings were not considered for the analysis. However, only $1.8 \%$ of the whole recording time was thus excluded. Third, the size of our patient population was fairly small. Fourth, 
Table 2 Number of total and specific asynchronies per minute as well as other respiratory parameters

\begin{tabular}{|c|c|c|c|c|c|c|c|c|c|c|}
\hline & \multicolumn{6}{|c|}{ Study period } & \multirow{3}{*}{$\begin{array}{l}\text { Repeated- } \\
\text { measures } \\
\text { ANOVA } \\
p\end{array}$} & \multicolumn{3}{|c|}{$\begin{array}{l}\text { Pairwise comparisons } \\
\text { (Newman-Keuls) }\end{array}$} \\
\hline & \multicolumn{2}{|l|}{ PS1 } & \multicolumn{2}{|l|}{ NAVA } & \multicolumn{2}{|l|}{ PS2 } & & NAVA & NAVA & \\
\hline & Median & $\begin{array}{l}\text { Centile } \\
25-75\end{array}$ & Median & $\begin{array}{l}\text { Centile } \\
25-75\end{array}$ & Median & $\begin{array}{l}\text { Centile } \\
25-75\end{array}$ & & PS1 & PS2 & PS2 \\
\hline $\mathrm{Td}(\mathrm{ms})$ & 178 & $139-245$ & 69 & $57-85$ & 199 & $135-256$ & $<0.001$ & $p<0.05$ & $p<0.05$ & NS \\
\hline Tiex (ms) & 204 & $117-345$ & 126 & $111-136$ & 220 & $127-366$ & 0.016 & $p<0.05$ & $p<0.05$ & NS \\
\hline $\mathrm{AI}(\%)$ & 12.0 & $4.8-26.4$ & 4.5 & $2.6-9.9$ & 12.8 & $6.6-28.7$ & 0.016 & $p<0.05$ & $p<0.05$ & NS \\
\hline Total asynchronies $(n / \mathrm{min})$ & 3.15 & $1.18-6.40$ & 1.21 & $0.54-3.36$ & 3.04 & $1.22-5.31$ & 0.032 & $p<0.05$ & $p<0.05$ & NS \\
\hline Ineffective efforts ( $\mathrm{n} / \mathrm{min})$ & 0.81 & $0.02-1.92$ & 0.00 & $0.00-0.00$ & 0.67 & $0.11-1.70$ & $<0.001$ & $p<0.05$ & $p<0.05$ & NS \\
\hline Late cycling $(n / \mathrm{min})$ & 0.12 & $0-0.63$ & 0.00 & $0.00-0.00$ & 0.09 & $0.0-1.15$ & $<0.001$ & $p<0.05$ & $p<0.05$ & NS \\
\hline Double triggering $(\mathrm{n} / \mathrm{min})$ & 0.00 & $0.00-0.04$ & 0.78 & $0.46-2.42$ & 0.00 & $0.00-0.00$ & $<0.001$ & $p<0.05$ & $p<0.05$ & NS \\
\hline Premature cycling ( $\mathrm{n} / \mathrm{min})$ & 0.14 & $0.00-0.41$ & 0.00 & $0.00-0.00$ & 0.00 & $0.00-0.48$ & $<0.001$ & $p<0.05$ & $p<0.05$ & NS \\
\hline Autotriggering $(\mathrm{n} / \mathrm{min})$ & 0.14 & $0.00-0.65$ & 0.09 & $0.00-0.74$ & 0.09 & $0.00-0.69$ & 0.555 & - & - & - \\
\hline MV $(1 / \mathrm{min})$ & 8.8 & $7.0-11.9$ & 9.2 & $7.9-12.4$ & 8.8 & $8.0-12.2$ & 0.293 & - & - & - \\
\hline VTi (ml/kg) & 7.3 & $6.3-7.9$ & 6.6 & $6.1-7.3$ & 7.5 & $6.9-8.4$ & $<0.001$ & $p<0.05$ & $p<0.05$ & NS \\
\hline $\mathrm{RR}(n$ cycles $/ \mathrm{min})$ & 18.8 & $15.6-25.1$ & 22.9 & $20.6-30.7$ & 19.1 & $16.4-28.4$ & 0.002 & $p<0.05$ & $p<0.05$ & NS \\
\hline Pawm $\left(\mathrm{cmH}_{2} \mathrm{O}\right)$ & 10.2 & $9.5-12.4$ & 9.6 & $8.7-11.7$ & 10.2 & $9.4-12.7$ & $<0.001$ & $p<0.05$ & $p<0.05$ & NS \\
\hline
\end{tabular}

PS1 first period of ventilation under pressure support, NAVA period asynchrony events/ventilator respiratory rate + ineffective of ventilation under NAVA, $P S 2$ second period of ventilation under efforts $) \times 100, M V$ minute ventilation, $V T i$ indexed tidal volume, pressure support, $T d$ trigger delay, Tiex inspiratory time in excess, $R R$ ventilator respiratory rate, Pawm mean airway pressure $A I$ asynchrony index (expressed in percentage) $=$ (number of

even if the level of assistance in NAVA has been determined according to the usual procedure described by the manufacturer and to previous studies (NAVA gain or proportionality factor between Eadi and pressure delivered by the ventilator, set so as to obtain the same peak pressure in NAVA as in PS) [25, 26], the comparability of assistance levels in PS and NAVA is questionable. Indeed, the airway pressure curves have different profiles as illustrated in Figs. 1 and 3, and Pawm is significantly lower in NAVA than in PS, as demonstrated by our results and as previously described [26]. Finally the expiratory trigger criterion in PS (chosen by the clinician in charge of the patient) for the eight obstructive patients included in our study was between 25 and $30 \%$ of the maximal flow value. This means that this criterion had not been optimized for these eight obstructive patients [27], which could have influenced patient-ventilator synchrony parameters.

Td was significantly shorter under NAVA, which is easily explained by the fact that the Eadi, an expression of the respiratory center's activity, is used to trigger the ventilator, rather than a pneumatic signal located at the airway opening or inside the ventilator. The significant reduction of Td in NAVA compared with PS should be attenuated by the fact that, under NAVA, according to a recent publication [28], not every respiratory cycle is triggered by the Eadi because of the first-come firstserved algorithm used for triggering by the commercially available system. However, as in our study $80 \%$ (58-89\%) of the respiratory cycles were triggered by the Eadi in NAVA, there was still a significant advantage for most patients. Under NAVA, no patient had mean Td above $150 \mathrm{~ms}$, whereas it was above this threshold in $72.7 \%$ of patients under PS. This is likely of clinical importance, as this delay of $150 \mathrm{~ms}$ corresponds to the conscious threshold of perception, a potential source of discomfort during the triggering process [29]. In PS, a significant inspiratory effort (estimated from the pressure-time product) is needed to trigger the ventilator [30]. In contrast, with NAVA (when the ventilator's delivered cycle is triggered by the Eadi), as the ventilator's delivered pressurization immediately follows the increase in Eadi signal (without any depression on the pressure-time curve), no inspiratory effort is theoretically needed to trigger the ventilator. As obstructive patients must overcome the intrinsic PEEP due to air trapping to trigger the ventilator in PS, they often present major trigger asynchronies with long trigger delays and high number of ineffective efforts $[20,31]$ associated with increased work of breathing (WOB) [32]. Because in NAVA the triggering process is independent of air trapping, NAVA could be particularly attractive to improve trigger asynchronies in these patients, as demonstrated in a recent study by Spahija et al. [26]. However, the results of that study might overestimate the benefits of NAVA triggering compared with PS, as the expiratory trigger was set in PS at a low value of $5 \%$, which could have increased hyperinflation under PS and thereby worsened patientventilator synchrony under PS [27, 33]. In contrast, our study was performed with usual (but, as previously mentioned, not optimized) clinical settings for expiratory trigger (set between $25 \%$ and $30 \%$ ) and also shows that 
there was no ineffective effort under NAVA whereas there were ineffective efforts under PS.

Delayed cycling was improved with NAVA, with Tiex reduced by more than $50 \%$ compared with PS. Theoretically, patient-ventilator synchrony should be nearly perfect with NAVA. However, because in NAVA the ventilator's delivered assist cycles off into exhalation when the Eadi decreases to $70 \%$ of the maximal Eadi value, there is an inherent delay between the end of the neural inspiratory time and the end of the assistance delivered by the ventilator. We found an expected residual Tiex of 126 ms (111-136 ms). Tiex in NAVA is, however, very short and under the threshold of consciousness of $150 \mathrm{~ms}$. The significant reduction of Tiex under NAVA compared with PS is important, as the presence of Tiex is associated with increased WOB [34, 35] and promotes dynamic hyperinflation [27]. As delayed cycling occurs mostly in patients with obstructive pulmonary disease (because of changes in instantaneous flow in the airways due to obstruction that delays the moment at which the expiratory set criterion is reached) [31, 32], the NAVA technology should be, also for that reason, of particular interest in this subgroup of patients. It is important to note that, despite the improvement of delayed cycling in NAVA, we did not find more premature cycling than in PS. In fact, the number of premature cycling is even reduced in NAVA compared with PS.

With NAVA, in contrast to what Colombo et al. [25] have previously described, more double triggering was present than under PS. This increase in double triggering can probably be explained by technical reasons. Indeed, the filtered Eadi signal used by NAVA to command the ventilator sometimes has a biphasic aspect. In this case (63.1\% of the total number of double triggering events in NAVA in our study), the initial decrease in the Eadi signal after the first peak is interpreted by the NAVA software as the cycling criterion which stops the ventilator's delivered pressurization. A new increase in the Eadi signal immediately follows this premature expiratory cycling and induces a new pressurization. This probably does not have major clinical importance, as the presence of double triggering is probably not associated with increased WOB. However, it is possible that this phenomenon is a source of discomfort for some patients. As our study was not designed to evaluate patient comfort, this point should be further investigated.

Despite the fact that in NAVA every Eadi signal variation is immediately followed by pressurization from the ventilator, we found no increase in autotriggering.
When autotriggering was present in NAVA, it was usually the consequence of artifacts on the Eadi signal.

Our study shows that there are overall fewer asynchronies in NAVA compared with PS, which confirms our hypothesis that NAVA can improve patient-ventilator interaction. The number of patients with $\mathrm{AI}>10 \%$ was also reduced by more than $50 \%$ with NAVA compared with PS. Of note, we found twice as many patients with AI $>10 \%$ in PS than Thille et al. [18]. This is probably related to the fact that we detected asynchronies not only on the basis of flow and pressure signal as Thille et al. did, but also on a reliable Eadi signal. Our results are in line with those of Colombo et al. [25], who found, taking into account only ineffective efforts and double triggering in the AI, $36 \%$ of patients with $\mathrm{AI}>10 \%$ under PS.

Despite minute volume being comparable under NAVA and PS, it is interesting to note that VTi was lower with NAVA and in the lower part of the range defined as safe by the acute respiratory distress syndrome (ARDS) network [36], suggesting, as previously reported [25], a possible protective effect of NAVA against volutrauma in such patients. This could be related to the fact that in NAVA, in contrast to PS, the amount of pressure delivered by the ventilator is proportional to the Eadi, which is a direct expression of the patient's inspiratory effort. NAVA could thereby prevent overassist. This hypothesis should be further investigated.

\section{Conclusions}

NAVA can improve patient-ventilator interaction in intubated patients by reducing Td, suppressing ineffective efforts, and reducing Tiex and the total number of asynchronies. These effects can be explained by the use of the Eadi, a direct expression of the respiratory center activity, to trigger and cycle off the ventilator as well as to the potential of NAVA to prevent overassist.

As a reduced number of asynchronies is associated with shorter duration of mechanical ventilation $[18,20]$, NAVA could prove beneficial in this patient population. Further studies should now aim to determine whether this improved synchrony can impact patient outcome.

Acknowledgments The authors wish to thank the Lancardis Foundation for its financial support, and Dr. Angèle Gayet-Ageron, Division of Clinical Epidemiology, University Hospital and Faculty of Medicine of Geneva, University of Geneva, Switzerland for her invaluable help with statistics. 


\section{References}

1. Carson SS, Cox CE, Holmes GM, Howard A, Carey TS (2006) The changing epidemiology of mechanical ventilation: a population-based study. J Intensive Care Med 21:173-182

2. Needham DM, Bronskill SE, Sibbald WJ, Pronovost PJ, Laupacis A (2004) Mechanical ventilation in Ontario, 1992-2000: incidence, survival, and hospital bed utilization of noncardiac surgery adult patients. Crit Care Med 32:1504-1509

3. Needham DM, Bronskill SE, Calinawan JR, Sibbald WJ, Pronovost PJ, Laupacis A (2005) Projected incidence of mechanical ventilation in Ontario to 2026: preparing for the aging baby boomers. Crit Care Med 33:574-579

4. Esteban A, Anzueto A, Alia I, Gordo F, Apezteguia C, Palizas F, Cide D, Goldwaser R, Soto L, Bugedo G, Rodrigo C, Pimentel J, Raimondi G, Tobin MJ (2000) How is mechanical ventilation employed in the intensive care unit? An international utilization review. Am J Respir Crit Care Med 161:1450-1458

5. Rose L, Presneill JJ, Johnston L, Nelson S, Cade JF (2009) Ventilation and weaning practices in Australia and New Zealand. Anaesth Intensive Care 37:99-107

6. Girard TD, Kress JP, Fuchs BD, Thomason JW, Schweickert WD, Pun BT, Taichman DB, Dunn JG, Pohlman AS, Kinniry PA, Jackson JC, Canonico AE, Light RW, Shintani AK, Thompson JL, Gordon SM, Hall JB, Dittus RS, Bernard GR, Ely EW (2008) Efficacy and safety of a paired sedation and ventilator weaning protocol for mechanically ventilated patients in intensive care (awakening and breathing controlled trial): a randomised controlled trial. Lancet 371:126-134

7. Kress JP, Pohlman AS, O'Connor MF, Hall JB (2000) Daily interruption of sedative infusions in critically ill patients undergoing mechanical ventilation. N Engl J Med 342:1471-1477

8. Schweickert WD, Gehlbach BK, Pohlman AS, Hall JB, Kress JP (2004) Daily interruption of sedative infusions and complications of critical illness in mechanically ventilated patients. Crit Care Med 32:1272-1276

9. Larsson L, Li X, Edstrom L, Eriksson LI, Zackrisson H, Argentini C, Schiaffino S (2000) Acute quadriplegia and loss of muscle myosin in patients treated with non depolarizing neuromuscular blocking agents and corticosteroids: mechanisms at the cellular and molecular levels. Crit Care Med 28:34-45
10. Garnacho-Montero J, Madrazo-Osuna J, Garcia-Garmendia JL, Ortiz-Leyba C, Jimenez-Jimenez FJ, BarreroAlmodovar A, Garnacho-Montero MC, Moyano-Del-Estad MR (2001) Critical illness polyneuropathy: risk factors and clinical consequences. A cohort study in septic patients. Intensive Care Med 27:1288-1296

11. Levine S, Nguyen T, Taylor N, Friscia ME, Budak MT, Rothenberg P, Zhu J, Sachdeva R, Sonnad S, Kaiser LR, Rubinstein NA, Powers SK, Shrager JB (2008) Rapid disuse atrophy of diaphragm fibers in mechanically ventilated humans. N Engl J Med 358:1327-1335

12. Futier E, Constantin JM, Combaret L, Mosoni L, Roszyk L, Sapin V, Attaix D, Jung B, Jaber S, Bazin JE (2008) Pressure support ventilation attenuates ventilator-induced protein modifications in the diaphragm. Crit Care 12:R116

13. Vassilakopoulos T, Petrof BJ (2004) Ventilator-induced diaphragmatic dysfunction. Am J Respir Crit Care Med 169:336-341

14. Putensen $\mathrm{C}$, Zech $\mathrm{S}$, Wrigge $\mathrm{H}$, Zinserling J, Stuber F, Von Spiegel T, Mutz N (2001) Long-term effects of spontaneous breathing during ventilatory support in patients with acute lung injury. Am J Respir Crit Care Med 164:43-49

15. Yamada Y, Du HL (2000) Analysis of the mechanisms of expiratory asynchrony in pressure support ventilation: a mathematical approach. J Appl Physiol 88:2143-2150

16. Tobin MJ, Jubran A, Laghi F (2001) Patient-ventilator interaction. Am J Respir Crit Care Med 163:1059-1063

17. MacIntyre N, Nishimura M, Usada $Y$, Tokioka H, Takezawa J, Shimada Y (1990) The Nagoya conference on system design and patient-ventilator interactions during pressure support ventilation. Chest 97:1463-1466

18. Thille AW, Rodriguez P, Cabello B, Lellouche F, Brochard L (2006) Patient-ventilator asynchrony during assisted mechanical ventilation. Intensive Care Med 32:1515-1522

19. Kondili E, Prinianakis G, Georgopoulos D (2003) Patient-ventilator interaction. Br J Anaesth 91:106-119

20. Chao DC, Scheinhorn DJ, StearnHassenpflug M (1997) Patientventilator trigger asynchrony in prolonged mechanical ventilation. Chest 112:1592-1599
21. Sinderby C, Navalesi P, Beck J, Skrobik Y, Comtois N, Friberg S, Gottfried SB, Lindstrom L (1999) Neural control of mechanical ventilation in respiratory failure. Nat Med 5:1433-1436

22. Piquilloud L, Vignaux L, Tassaux D, Jolliet P (2009) Can neurally adjusted ventilatory assist (NAVA) improve patient-ventilator interaction? A preliminary study. Intensive Care Med 35(Suppl 1):S21

23. Barwing J, Ambold M, Linden N, Quintel M, Moerer O (2009) Evaluation of the catheter positioning for neurally adjusted ventilatory assist. Intensive Care Med 35:1809-1814

24. Vignaux L, Vargas F, Roeseler J, Tassaux D, Thille AW, Kossowsky MP, Brochard L, Jolliet P (2009) Patientventilator asynchrony during noninvasive ventilation for acute respiratory failure: a multicenter study. Intensive Care Med 35:840-846

25. Colombo D, Cammarota G, Bergamaschi V, De Lucia M, Corte FD, Navalesi P (2008) Physiologic response to varying levels of pressure support and neurally adjusted ventilatory assist in patients with acute respiratory failure. Intensive Care Med 34:2010-2018

26. Spahija J, de Marchie M, Albert M, Bellemare P, Delisle S, Beck J, Sinderby C (2010) Patient-ventilator interaction during pressure support ventilation and neurally adjusted ventilatory assist. Crit Care Med 38:518-526

27. Tassaux D, Gainnier M, Battisti A, Jolliet P (2005) Impact of expiratory trigger setting on delayed cycling and inspiratory muscle workload. Am J Respir Crit Care Med 172:1283-1289

28. Breatnach C, Conlon NP, Stack M, Healy M, O'Hare BP (2010) A prospective crossover comparison of neurally adjusted ventilatory assist and pressure-support ventilation in a pediatric and neonatal intensive care unit population. Pediatr Crit Care Med 11:7-11

29. Whitelaw WA, Derenne JP, Milic-Emili J (1975) Occlusion pressure as a measure of respiratory center output in conscious man. Respir Physiol 23:181-199

30. Sassoon CS, Gruer SE (1995) Characteristics of the ventilator pressure- and flow-trigger variables. Intensive Care Med 21:159-168

31. Nava S, Bruschi C, Fracchia C, Braschi A, Rubini F (1997) Patient-ventilator interaction and inspiratory effort during pressure support ventilation in patients with different pathologies. Eur Respir J $10: 177-183$ 
32. Nava S, Bruschi C, Rubini F, Palo A, Iotti G, Braschi A (1995) Respiratory response and inspiratory effort during pressure support ventilation in COPD patients. Intensive Care Med 21:871-879

33. MacIntyre N (2010) Talk to me! Toward better patient-ventilator communication. Crit Care Med 38:714-715
34. Jubran A, Van de Graaff WB, Tobin MJ (1995) Variability of patient-ventilator interaction with pressure support ventilation in patients with chronic obstructive pulmonary disease. Am J Respir Crit Care Med 152:129-136

35. Parthasarathy S, Jubran A, Tobin MJ (1998) Cycling of inspiratory and expiratory muscle groups with the ventilator in airflow limitation. Am J Respir Crit Care Med 158:1471-1478
36. Stewart TE, Meade MO, Cook DJ, Granton JT, Hodder RV, Lapinsky SE, Mazer CD, McLean RF, Rogovein TS, Schouten BD, Todd TR, Slutsky AS (1998) Evaluation of a ventilation strategy to prevent barotrauma in patients at high risk for acute respiratory distress syndrome. Pressureand volume-limited ventilation strategy group. N Engl J Med 338:355-361 